\title{
The intergranular oxidation susceptibility of thermally-treated Alloy 600
}

DOI:

10.1016/j.corsci.2016.11.004

Document Version

Accepted author manuscript

Link to publication record in Manchester Research Explorer

\section{Citation for published version (APA):}

Bertali, G., Scenini, F., \& Burke, G. (2017). The intergranular oxidation susceptibility of thermally-treated Alloy 600. Corrosion Science, 114, 112-122. https://doi.org/10.1016/j.corsci.2016.11.004

\section{Published in:}

Corrosion Science

\section{Citing this paper}

Please note that where the full-text provided on Manchester Research Explorer is the Author Accepted Manuscript or Proof version this may differ from the final Published version. If citing, it is advised that you check and use the publisher's definitive version.

\section{General rights}

Copyright and moral rights for the publications made accessible in the Research Explorer are retained by the authors and/or other copyright owners and it is a condition of accessing publications that users recognise and abide by the legal requirements associated with these rights.

\section{Takedown policy}

If you believe that this document breaches copyright please refer to the University of Manchester's Takedown Procedures [http://man.ac.uk/04Y6Bo] or contact uml.scholarlycommunications@manchester.ac.uk providing relevant details, so we can investigate your claim.

\section{OPEN ACCESS}




\title{
THE INTERGRANULAR OXIDATION SUSCEPTIBILITY OF THERMALLY-TREATED ALLOY 600
}

\author{
G. Bertali ${ }^{1}$, F. Scenini ${ }^{1}$, M. G. Burke ${ }^{1}$. \\ ${ }^{1}$ The University of Manchester, Material Performance Centre, Manchester (UK)
}

\begin{abstract}
The oxidation behaviour of thermally-treated Alloy 600 was studied using hydrogenated steam at $480^{\circ} \mathrm{C}$, environment known to simulate pressurized water reactors conditions, and subsequently analyzed using analytical electron microscopy. Focused Ion Beam and analytical transmission electron microscopy provided definitive evidence of localized intergranular carbides decomposition and the formation of an intergranular $\mathrm{Cr}$-rich oxide embryo. These results are discussed in this paper in terms of early stages of preferential intergranular oxidation and grain boundary migration, carbide decomposition, GB pinning and the effect of local carbon enrichments in the matrix.
\end{abstract}

Key words: Alloy 600, preferential intergranular oxidation, carbides decomposition, AEM. 


\section{Introduction}

The susceptibility of Alloy 600 to intergranular stress corrosion cracking (IGSCC) in pressurized water reactor (PWR) primary water environment is well-known and it has been a major in-service issue in the past decades [1-3]. The Internal Oxidation mechanism of Scott and Le Calvar has been proposed for IGSCC initiation $[4,5]$ in PWR primary water environment; however, this mechanism in relation to primary water stress corrosion cracking (PWSCC) has considerably changed since it was proposed. Internal oxidation is defined as the precipitation of discrete internal oxide particles [6]. However, the cause for PWSCC has been associated with the formation of preferential intergranular oxide [7-13] in both PWR simulated primary water as well as in accelerated SCC tests. Therefore, even though preferential intergranular oxidation can occur deep into the matrix, it should not be considered internal oxidation in the classical sense, since there is connectivity with the outer surface. Consequently, and strictly speaking, the terminology "internal oxidation" is often incorrectly used to explain the mechanism of SCC. A mechanistic understanding of IGSCC is key to the in-plant management of Alloy 600 components. Consequently, several parametric studies were undertaken in the past decades with the aim of studying the effect of temperature [14-16], cold work $[15,17]$, residual stress $[18,19]$ and heat treatments [20]. It was found that a very cost effective way to mitigate SCC was by thermal treatment and this was studied for the first time in 1977 by Domian et al. [20]. Specifically, thermally-treated (TT) Alloy 600 was shown to have higher IGSCC resistance in deareated, high-purity water than does mill-annealed (MA) and solution-annealed (SA) condition [20-22], though not to be immune. Subsequent studies demonstrated that a semi-continuous network of grain boundary (GB) carbides formed during thermal treatment can enhance SCC resistance of Alloy 600 in caustic environment [23] and reducing environment (e.g. hydrogenated primary water at elevated temperature) [24-27]. The main reason for this improved IGSCC resistance of Alloy 600TT was associated with the 
presence of grain boundary carbides, which delay crack initiation and decrease crack growth rate [28]. Considerable interest has been focused on the role of the Cr-rich carbides themselves as the mitigation of IGSCC and two main mechanisms have been proposed: the first is based on the mechanical effect of intergranular carbides whereas the second mainly focuses on the electrochemical/chemical effects that carbides can have on IGSCC and intergranular oxidation. With respect to the mechanical mechanism, Bruemmer et al. [29] proposed that intergranular carbides serve as effective dislocation sources, which promote crack blunting, thus reducing crack growth rate and grain boundary sliding. Alternatively, carbides might create a more tortuous path for intergranular crack propagation, and, therefore, reduce the crack growth rate by mechanically interfering with crack propagation [30].

On the other hand, Was et al. [30] suggested that the intergranular Cr-rich carbide oxidization might result in the formation of a more stable and protective Cr-rich oxide at the crack tip, hence reducing the intergranular oxidation rate and crack propagation. Dugdale et al. [32] also proposed that a more dense and protective oxide is formed around intergranular carbides. Furthermore, Persaud et al. [11] suggested that oxidation of $\mathrm{Cr}$ carbides at the grain boundary might impede inwards oxygen diffusion, and consequently improve Alloy 600 SCC resistance. However, despite several laboratories studied the oxidation behaviour of intergranular carbides [30,32-34], there is still little evidence of this behaviour. Burke et al. [32] in their analyses of cold-work Alloy 600 SCC fracture surface were the first to identify the presence of localised oxidation on intergranular $\mathrm{M}_{7} \mathrm{C}_{3}$ carbides and localised dissolution. Thus, the effect of a semicontinuous network of intergranular carbides on intergranular oxidation merits further analysis, as the mechanism by which intergranular carbides affect the oxidation and SCC initiation is still not fully understood.

In the last few years, several researchers observed that during PWR simulated primary water oxidation Ni-based Alloy 600 and 690 grain boundaries deviate from their original position 10- 
$20 \mathrm{~nm}$ (depending on exposure conditions) and became asymmetrically depleted in both $\mathrm{Cr}$ and Fe [36-39], and suggested that this is due to grain boundary migration. However, only Bertali et al. $[10,35]$ unequivocally demonstrated, via analytical electron microscopy (AEM) and diffraction analysis that this elemental depletion was due to GB migration. In their solutionannealed Alloy 600 exposed to high-temperature $\mathrm{H}_{2}$-steam environment they identified a pronounced GB migration and suggested that this mechanism could play an important role in the early stages of the IGSCC initiation and preferential intergranular oxidation (PIO) processes. Recent experiments by the current authors were able to successfully identify and monitor the precursor phenomenon for IGSCC in PWRs [40]. They performed in situ analytical transmission electron microscopy (TEM) oxidation experiments using a gas environmental cell at elevated temperature and confirmed the occurrence of GB migration and preferential intergranular oxidation.

The aim of the present study is to investigate the initial stages of PIO for thermally-treated Alloy 600, in an environment known to accelerate PWR SCC without changing the oxidation behaviour [10,35], and compare this with the results published by the present authors on solution-annealed material tested under identical conditions. The focus of this work is on understanding the effect of the intergranular carbides on localised grain boundary migration and grain boundary pinning, carbide oxidation/decomposition and the role of carbon deriving from the carbide oxidation/decomposition.

\section{Experimental procedures}

\section{Material and sample preparation}

The material used in this study was Alloy 600 manufactured by B\&W Tubular Products Division and supplied by Westinghouse (heat \#93510). The material was provided in the lowtemperature mill-annealed condition, and the bulk composition is reported in Table 1 . The 
material was solution-annealed in air at $1100^{\circ} \mathrm{C}$ for 30 minutes and subsequently waterquenched to room temperature within 10 seconds in order to minimize the extent of intergranular carbide precipitation. The recrystallized coarse-grained $(200-400 \mu \mathrm{m})$ microstructure facilitated the investigations in this study. The material in the SA condition was exactly the same as used in previous by the current authors $[10,35]$. Some of the solutionannealed material was subsequently thermally-treated in air at $700^{\circ} \mathrm{C}$ for 15 hours and subsequently water-quenched to produce a semi-continuous network of $\mathrm{Cr}$-rich carbides along the grain boundaries.

Rectangular oxidation coupons $\left(20 \times 15 \times 2 \mathrm{~mm}^{3}\right)$ of TT Alloy 600 were cut from the heat-treated block of materials and metallographically polished with $3 \mu \mathrm{m}$ diamond suspension solution. The specimens were extracted several $\mathrm{mm}$ away from the surface, therefore any pre-oxidation that occurred during the heat-treatment was not considered a problem. The final polishing step was performed using an Oxide Polishing Suspension (OPS) solution, which allowed to remove any superficial deformation induced by mechanical polishing. In fact, it is known that a superficial deformed layer will have an impact on the alloy oxidation behaviour $[41,42]$. The OPS polishing procedure produces a strain-free surface and therefore can be considered to be representative of the bulk material.

\section{$\underline{\text { Hydrogenated steam oxidation system }}$}

The oxidation experiments were conducted in a low-pressure $\mathrm{H}_{2}$-steam environment at temperatures up to $480^{\circ} \mathrm{C}$ at a water flow rate of $1.8 \mathrm{~mL} / \mathrm{min}, \mathrm{H}_{2}$ flow rate of $35 \mathrm{~mL} / \mathrm{min}$ and a steam-to- $\mathrm{H}_{2}$ ratio of 62.16 . This system, which has been already employed in the past decade for oxidation experiments on Ni-based alloys [10,35,43], has been shown to accelerate the oxidation of the alloys while maintaining the appropriate thermodynamic conditions with respect to the $\mathrm{Ni} / \mathrm{NiO}$ transition. In fact, it is known that the maximum SCC susceptibility of 
Alloy 600 occurs at a potential of $+-80 \mathrm{mV} v s$. Ni/NiO transition which also corresponds to the window of potential where commercial pressurized water reactor (PWR) operate $[42,43]$.

The oxidation tests were conducted for 120 hours at $480^{\circ} \mathrm{C}$ in low pressure $\mathrm{H}_{2}$-steam environment at an $\mathrm{O}_{2}$ partial pressure of $9.9 \times 10^{-26} \mathrm{~atm}$, which is 24 times lower than the $\mathrm{Ni} / \mathrm{NiO}$ dissociation pressure at the test temperature. The conditions chosen for this study were exactly the same as for a paper recently published by the present authors [34]; additional details concerning the operation of the system are provided by Scenini et al. [45], who originally developed the low pressure H2-steam system [45] and also reported by Persaud et al. [11] who used an identical replica of the system.

\section{$\underline{\text { Microstructural characterization }}$}

The specimens were characterized prior to and after oxidation using a selection of complementary microstructural analysis techniques including field emission gun (FEG) scanning electron microscope (SEM), focused ion beam (FIB) microscopy and analytical transmission electron microscope (AEM). A Zeiss Merlin FEG-SEM equipped with an Oxford Instruments X-max 150 silicon drift detector (SDD) and an Oxford Instruments Extreme 100 windowless SDD for energy dispersive X-ray (EDX) microanalysis was used to characterize the as-polished samples surface before and after exposure. An FEI Helios NanoLab 660 DualBeam FIB was used to prepare site-specific cross-section in order to visualize the oxide and its penetration depth at selected high-angle grain boundaries (HAGBs) and to perform 3D slice and view analyses. A Through-Lens Detector (TLD), Mirror Detector (MD) and InColumn Detector (ICD) at high $(20 \mathrm{kV})$ and low accelerating voltage $(3-5 \mathrm{kV})$ were employed for electron imaging. 
Cross-section specimens were then extracted from the coupons using the TEM lift-out technique and thinned using the FIB to electron transparency. In order to characterize the baseline material microstructure, including type and extent of precipitation, several conventionally prepared samples were examined with TEM. These were $3.0 \mathrm{~mm}$ diameter disc samples obtained from the thermally-treated Alloy 600 were electropolished in $20 \% \mathrm{HClO}_{4}-$ $80 \% \mathrm{CH}_{3} \mathrm{OH}$ at $-33^{\circ} \mathrm{C}$ using a Struers Tenupol equipped with a Jubalo closed cycle refrigeration system. Initial AEM characterization of the TEM specimens was performed using an FEI Tecnai G2 T20 LaB 6 analytical TEM operated at $200 \mathrm{kV}$ and equipped with an Oxford Instruments windowless Xmax 80 TLE SDD and Aztec analysis system. Discrete STEM-EDX "spot analyses" were performed to measure composition at various locations along the HAGBs. These EDX spectra were quantified using the Aztec TEMQUANT software based on the CliffLorimer relation. Theorectical "k-factors" were used for EDX quantification. Additional analyses were performed at $200 \mathrm{kV}$ using an FEI Titan G2 80-200 aberration-corrected S/TEM with an X-FEG and ChemSTEM ${ }^{\mathrm{TM}}$ technology equipped with four SDDs for improved X-ray collection and EDX spectrum imaging analysis.

\section{Results}

Baseline material characterization

Several as-polished Alloy 600TT coupons were analysed in a FEG-SEM using the backscattered electron (BSE) imaging mode in order to examine in details the microstructure, to ensure the correct polishing procedure (i.e. obtain a strain-free surface) and to assess the extent of intergranular and intragranular carbides precipitation.

Detailed SEM examination revealed that the material had a recrystallized microstructure with a non-uniform distribution of coarse $(400 \mu \mathrm{m})$ and finer $(150 \mu \mathrm{m})$ grains and a considerable proportion of annealing twins; these results are consistent with the high temperature used for 
the annealing treatment $\left(1100{ }^{\circ} \mathrm{C}\right)$ [35], a representative low-magnification micrograph of Alloy 600TT microstructure is shown in Figure 1. Higher magnification analysis with secondary electrons (SE) and BSE imaging mode (Figure 2 (a) and (b)) revealed the presence of a semi-continuous network of intergranular precipitates along HAGBs as well as a large amount of intragranular precipitates. The intergranular precipitates appeared to have either an elongated or a globular morphology as evident in Figure 2. The real morphology of the precipitates cannot be inferred from 2D images; rather reconstructed from 3D data (e.g. FIB 3D slice-and-view). The precipitates seemed to have two distinct morphologies: fine discrete intragranular precipitates $(\sim 100 \mathrm{~nm})$ that were characterized by an elongated morphology, and other coarser $(\sim 300 \mathrm{~nm})$ precipitates, which had a more globular morphology. It is likely that the fine precipitates are elongated (Figure 2 (b)) because they are preferentially forming on dislocations.

Several HAGBs of the polished samples prior to oxidation were cross-sectioned using the FIB and then imaged in SE mode. From the analysis, no preferential etching of the grain boundaries was detected, thus confirming the successful polishing procedures with OPS in retaining the surface features. Moreover, it is possible to confirm the absence of any pre-existing intergranular oxide or carbide decomposition. A representative SE image of the HAGB crosssection prior to oxidation is reported in Figure 3.

Further analyses of the Alloy 600TT specimens were performed using analytical TEM. The electron diffraction confirmed that the intragranular precipitates were face centered cubic (fcc) semi-coherent $\mathrm{Cr}$-rich $\mathrm{M}_{23} \mathrm{C}_{6}$ carbides as shown in the inset of Figure 4. The lattice parameter of these $\mathrm{M}_{23} \mathrm{C}_{6}$ carbides is three time larger than the fcc matrix, and they exhibit the cube-cube orientation relationship with the matrix (inset of Figure 4). The carbides can exhibit a needle- 
like morphology as evident from the dark-field (DF) TEM image (Figure 4). TEM examinations revealed the presence of two types of intergranular precipitates. The coarse intergranular precipitates that appeared to have an elongated morphology were confirmed by SADP analysis to be pseudo-hexagonal heavily faulted $\mathrm{Cr}$-rich $\mathrm{M}_{7} \mathrm{C}_{3}$ carbides (exhibiting the classic streaking in the diffraction pattern), as visible from the BF and DF images reported in Figure 5 (a) and (b). Conversely the globular intergranular precipitates were identified as fcc semi-coherent $\mathrm{M}_{23} \mathrm{C}_{6}$ carbides (Figure 6 (a) and (b)). STEM-EDX microanalysis confirmed that these carbides were Cr-rich (Figure 7). STEM-EDX discrete "spot" and line-scan analyses confirmed that the HAGBs were markedly depleted in $\mathrm{Cr}$ (to $~ 10 \%$ wt) and that the depleted zone extended approximately $500 \mathrm{~nm}$ from the grain boundary into the matrix.

\section{$\underline{\text { SEM characterisation of the oxidized surface }}$}

Representative SE image of oxidized HAGBs, after $120 \mathrm{~h}$ exposure in $\mathrm{H}_{2}$-steam at $480{ }^{\circ} \mathrm{C}$ are shown in Figure 8; these GBs were identified via Electron Backscattered Diffraction analysis. SE SEM imaging of the oxidized surface revealed the presence of homogeneously distributed intragranular brightly-imaging features (nodules) along the entire specimen surface. Furthermore, a banded grain boundary structure, which appeared to protrude from the surface forming ridges on the specimen surface, was also visible. The surface nodules forming on Alloy 600 in this specific environment and temperature have been already extensively characterized by AEM and atom probe tomography and reported to be mainly composed of pure metallic $\mathrm{Ni}$ [35,45-47]. They have been extensively investigated and are believed to form as a result of internal oxidation and solvent diffusion to the surface [46,47].

High resolution SEM characterization of the bulged grain boundary structure revealed that the majority of HAGBs had a marked protruded region on both sides of the GBs, as evident in Figure 9 (a). The region with protruded grain boundary was considerably wide, extending for almost $1 \mu \mathrm{m}$ on either side of the HAGBs (Figure 9 (a)). A representative $3 \mathrm{kV}$ SEM-BSE 
image of the protruded HAGB shown in Figure 9 (b), it was possible to identify a darklyimaging layer, and hence low atomic number. This layer was observed astride of the GB and it indicates the presence of a superficial oxide. The coverage of the oxide did not fully extend across the grains and was not detected along all the GBs as visible from Figure 8 to Figure 10. The main reason why the oxide was not detected is because of SEM surface analysis limitations. In fact, even at low accelerating voltages $(3-5 \mathrm{kV})$ the beam interaction volume is big (between 50 to $100 \mathrm{~nm}$ ) compared to the thickness of the superficial oxide (few tens of $\mathrm{nm})$. Therefore, the SEM signal is an average between the superficial oxide and the underneath metal. The presence of a continuous superficial oxide was confirmed by FIB cross-section and STEM-EDX analyses and is discussed in detail in the next sections.

Analysis of the surface using the secondary electron imaging mode also showed that most of the HAGBs appeared straight and did not markedly deviate from their original plane after the exposure in $\mathrm{H}_{2}$-steam environment (Figure 10 (a)). The few GB undulations observed on Alloy 600TT (Figure 9) are most probably related to the applied thermal-treatment and intergranular carbides precipitation and not due to GB migration. This finding suggests that Alloy 600TT did not undergo extensive grain boundary migration during the exposure in $\mathrm{H}_{2}$-steam environment at $480^{\circ} \mathrm{C}$ unlike the response of Alloy 600SA tested under identical conditions [35], where both the extent and frequency of undulations was markedly higher. The lower extent and frequency of GB undulations might be an evidence for the higher resistance to diffusion-induced grain boundary migration (DIGM) of Alloy 600TT compared to the solutionannealed material. Although no marked GB migration was observed, HAGBs did not appear immune to intergranular oxide penetration. In fact, BSE analysis revealed the presence of a darkly-imaging line (low atomic number) which was observed to follow the HAGBs and it is therefore an indication of the presence of an intergranular oxide (Figure 10 (b)). The presence 
of the superficial and intergranular oxides was confirmed by STEM-EDX microanalysis and is discussed in detail in the next section.

\section{Characterisation of Oxidized GBs: FIB-Prepared Cross-Section Specimens}

In order to study the susceptibility to preferential intergranular oxide penetration and grain boundary migration of Alloy 600TT HAGBs, several HAGBs were cross-sectioned using FIB and examined using low kV FEG-SEM imaging. A total of 20 HAGBs were analysed. Figure 11 shows a representative SE image of an Alloy 600TT FIB cross-sectioned GB. The presence of an oxide layer on the surface above the GB and a protruded region on both sides of the boundary is visible in this cross-section specimen (Figure 11). All the HAGBs analysed had negligible intergranular oxidation (less than few tens of $\mathrm{nm}$ ) and, therefore, it is postulated that the superficial oxide protected the "covered" GBs from intergranular oxide penetration, as visible in Figure 10. Furthermore, from the Alloy 600TT FIB cross-section analysis it was possible to observe that the intergranular carbides appeared to be partially decomposed during the exposure in $\mathrm{H}_{2}$-steam environment (Figure 11). It might be argued that the observed irregular shape of the intergranular carbides near the surface is due preferential polishing during FIB cross-sectioning. However, the base-line material characterization performed on Alloy 600TT HAGBs with FIB cross-section analysis and reported in the previous section did not reveal any irregular carbide shape. Lastly, all the cross-sectioned HAGBs showed negligible bowed and migrated regions beneath the darkly-imaging surface oxide (Figure 11); unpublished results from the authors with the FIB 3D slice-and-view technique confirmed that no migration occurred during the oxidation.

\section{$\underline{\text { AEM Characterization of Intergranular Oxide Penetration }}$}

AEM analysis was employed to characterize the near-surface region of the oxidized Alloy 600TT HAGBs. A total of 5 FIB-prepared cross-section specimens containing at least one 
HAGBs were analysed via TEM. The images reported in the Figures are considered to be representative examples for the GB analysed. TEM bright-field (BF) and dark-field (DF) images of an oxidized HAGB are shown in Figure 12 (a) and (b), respectively. The BF image revealed the presence of coarse intergranular precipitates (Figure 12 (a)) and selected area electron diffraction pattern (SADP) analysis confirmed that the precipitates just below the surface were pseudo-hexagonal $\mathrm{M}_{7} \mathrm{C}_{3}$ carbides. DF-TEM images highlighted that the intergranular carbides that intersected the surface had an unusual shape because they were decomposed during the exposure in $\mathrm{H}_{2}$-steam environment. In fact, DF-TEM and SADP analyses provide crystal structure information (not atomic $\mathrm{Z}$ contrast) and are used to identify different precipitates (e.g. carbides and /or oxides). In the present case Figure 12 (b). report a DF image of the intergranular $\mathrm{M}_{7} \mathrm{C}_{3}$ carbide, which was identified via electron diffraction. The contrast variation is due to the selection of a specific diffracted "spot" which is characteristic of the carbide and is used to form the DF TEM image. The reason why the two carbides have different contrast in Figure 12 (b) is due the fact that the carbides have different orientation. All the HAGBs were found to have the locally "decomposed" carbides in the near-surface region. These regions were subsequently analysed using STEM-EDX microanalysis techniques. A series of Titan "ChemiSTEM" STEM-EDX SDD spectrum images are shown in Figure 13. The STEM-EDX data confirmed that the $\mathrm{M}_{7} \mathrm{C}_{3}$ carbides intersecting the outer surface were partially decomposed as shown in the $\mathrm{Cr} \mathrm{K} \alpha$ and $\mathrm{Ni} \mathrm{K} \alpha$ spectrum images of Figure 13, which confirm the presence of Cr-enriched and very Ni-depleted regions. The analyses also highlighted a strong $\mathrm{Ni}$ enrichment at the location where the intergranular carbides were partially decomposed, as visible from the Ni K $\alpha$ spectrum images reported in Figure 13 and Figure 14. The C K $\alpha$ EDX spectrum images were not analysed and are not displayed in this manuscript because they can provide misleading information even at a qualitative level. In fact, $\mathrm{C}$ is a very light element and its accurate detection is beyond the SDD capabilities. Moreover, 
it is extremely difficult to avoid $\mathrm{C}$ contamination on metallic specimens. In particular the free $\mathrm{C}$ on the surface of the FIB lift-out specimen (coming from the environment) is extremely mobile and tends to build up in the region where the STEM probe is focused. Therefore, during STEM-EDX spectrum imaging (which normally last 30 minutes) $\mathrm{C}$ tends to build up in the region of analysis creating artefacts.

STEM-EDX microanalysis of the same HAGB analysed in this work via TEM confirmed the presence of a continuous and $\mathrm{Cr}$ and Fe-rich oxide above the $\mathrm{GB}$ at the intersection between the GB and the surface, as visible in the $\mathrm{O} \mathrm{K} \alpha, \mathrm{Cr} \mathrm{K} \alpha$ and $\mathrm{Fe} \mathrm{K} \alpha$ spectrum images of Figure 14. These results suggested the formation of Chromite-type spinel oxide (face centred cubic structure). However, it was not possible to conclusively identify the oxide crystal structure via diffraction analysis because this superficial oxide was extremely thin and in correspondence of the specimen Pt layer interface. This surface oxide appeared to protect the underneath material from both internal and intergranular oxidation, despite the presence of a complex and branched embryo of intergranular Cr-rich oxide along the GB $(50 \mathrm{~nm})$. Moreover, the $\mathrm{Cr} \mathrm{K} \alpha$ spectrum image (Figure 14) confirmed that the previously identified intergranular $\mathrm{M}_{7} \mathrm{C}_{3}$ carbide was partially decomposed so that the free $\mathrm{Cr}$ can contribute to the formation of a superficial Cr-rich oxide. Beneath the Cr-rich oxide STEM-EDX analysis confirmed a marked $\mathrm{Cr}$ and Fe depletion and a $\mathrm{Ni}$ enrichment in the region where the carbide was originally present.

Detailed analysis of the STEM-EDX data confirmed that there was a complete $\mathrm{Cr}$ and $\mathrm{Fe}$ depletion and strong Ni enrichment on both sides of the HAGBs where the ridges are formed, as visible in Figure 14. This suggests that the GB ridges are mainly composed of pure metallic Ni.

\section{Discussion}

The detailed examinations of thermally-treated Alloy 600 after exposure in high-temperature $\mathrm{H}_{2}$-steam environment can be compared with the results reported by Bertali et al. $[10,35]$ on 
Alloy 600SA which had been tested under identical conditions. Interestingly, whilst Alloy 600SA exhibited deep intergranular oxide penetration and local GB migration (the latter is believed to be a precursor of intergranular oxidation), Alloy 600TT showed a pronounced resistance to preferential intergranular oxide penetration and HAGBs migration.

The preferential intergranular oxide penetration of Alloy 600TT was found to be less than 50 $\mathrm{nm}$ (Figure 11) and this value is markedly lower than what was reported for Alloy 600SA tested under identical conditions $[10,35,47]$. Therefore, it is believed that the surface oxide protected the HAGBs from the external environment preventing further oxidation and grain boundary oxide penetration. This enhanced resistance to PIO is thus related to the presence of intergranular carbides in the near-surface region. The coarse intergranular $\mathrm{M}_{7} \mathrm{C}_{3}$ carbides in the near-surface region observed by TEM (Figure 12) were preferentially decomposed in the $\mathrm{H}_{2}$-steam environment. The STEM-EDX spectrum images shown in Figure 13 and Figure 14 also support the idea that $\mathrm{Cr}$-rich $\mathrm{M}_{7} \mathrm{C}_{3}$ carbides behave as a reservoir of $\mathrm{Cr}$ during the oxidation in high-temperature $\mathrm{H}_{2}$-steam. Several researchers have studied the behaviour of carbides in PWR primary water environment [30-34]. However, the oxidation/decomposition of the Crrich carbides could not be confirmed in such environment, despite thermodynamic calculations from Laghoutaris et al. [48] showed that Cr-rich carbides should be more easily oxidized than the base metal in PWR primary water. The present study, and specifically the STEM-EDX microanalyses of the oxidized Alloy 600TT, confirmed that intergranular Cr-rich carbides can be decomposed during high-temperature $\mathrm{H}_{2}$-steam exposure, an environment that is known to be relevant to PWR primary water $[11,35,45]$. The TEM and STEM-EDX analyses unequivocally showed that intergranular $\mathrm{M}_{7} \mathrm{C}_{3}$ carbides near the surface can decompose thereby providing a source of $\mathrm{Cr}$ for the formation of a surface $\mathrm{Cr}$-rich spinel oxide, and free C. However, the driving force responsible for the carbides decomposition is still unclear and is topic of on-going research. 
Although Alloy 600TT was found to be more resistant than Alloy 600SA, it was not immune to PIO. In fact, the presence of Cr-rich intergranular oxide embryo and pure Ni regions ahead the intergranular oxide and beneath the superficial oxide suggested that a PIO mechanism was active even it the Alloy 600TT. It was also observed that the pure Ni regions were situated at the same locations where the intergranular carbides were partially decomposed. This behaviour has been already observed by Yun Soo Lim et al. [49] and Sennour et al. [33]. Both laboratories detected in Alloy 600 tested in PWR simulated primary water the presence of an intermediate highly $\mathrm{N}$-enriched layer between the intergranualr $\mathrm{Cr}$-rich carbide and the oxidized matrix around it.

The detailed SEM and TEM analyses performed in this study on Alloy 600TT before and after the $\mathrm{H}_{2}$-steam exposure showed significant changes at HAGBs both on the surface and in the near-surface regions. Surface SE and BSE analyses revealed the presence of a wide and pronounced bulged surface oxide structure in the proximity of the grain boundaries (Figure 8 and Figure 9), with protruded regions present on both sides of the GBs and extending laterally for more than $500 \mathrm{~nm}$. This suggests that the thick surface oxide above Alloy 600TT HAGBs protect them from PIO. Detailed SEM examinations, specifically BSE imaging (Figure 10), highlighted the absence of any wavy/undulating appearance of HAGBs after exposure in $\mathrm{H}_{2}$ steam thus suggesting that Alloy 600TT GBs are not susceptible to migration during oxidation in $\mathrm{H}_{2}$-steam environment.

Furthermore, by comparing the current results with previous work by Bertali et al. [35] it was observed that Alloy 600SA was clearly more susceptible then Alloy 600TT to GB migration during high-temperature exposure in $\mathrm{H}_{2}$-steam. $\mathrm{Cr}$ and $\mathrm{Fe}$ depletion accompanied by $\mathrm{Ni}$ enrichment have also been previously observed on Alloy 600SA [10,35], and it was attributed to a grain boundary migration phenomenon. However, in the present case the $\mathrm{Cr}$ - and $\mathrm{Fe}$ - 
depleted region observed by AEM was narrower than what detected in Alloy 600SA and cannot be associated with a bugled/migrated GB region as it was for Alloy 600SA. STEM-EDX microanalysis of Alloy 600TT revealed a small bowed $\mathrm{Cr}$ - and $\mathrm{Fe}$-depleted region along with a continuous Cr-rich surface oxide. It should be noted that the presence of the Cr-depletion in the Alloy 600TT specimens may also be related to the intergranular precipitation of the Cr-rich $\mathrm{M}_{7} \mathrm{C}_{3}$ and $\mathrm{M}_{23} \mathrm{C}_{6}$ carbides during the $700^{\circ} \mathrm{C}$ ageing treatment. Furthermore, the intergranular carbide precipitation is frequently accompanied by local grain boundary excursions and pronounced Cr-depleted zones related to the growth of the carbides [49]. Therefore, in order to unequivocally differentiate the effect of GB migration from the one of carbides precipitation, the Fe depletion was used as a parameter to identify the HAGB migration caused by the oxidation process. T he reason why Alloy 600TT presented a smaller and sometimes negligible $\mathrm{Cr}$ and Fe-depleted migrated regions could be related to the GBs pinning effect of coarse intergranular carbides [30]. In fact, the presence of a semi-continuous network of intergranular Cr-rich $\mathrm{M}_{7} \mathrm{C}_{3}$ carbides might actively hinder the grain boundary motion making it difficult for a grain boundary to migrate laterally [30]. The GB pinning effect of intergranular carbides that mitigates migration is additive to the pinning effect provided by other second phases, such as Cr-rich oxide along the migrated GBs in Alloy 600SA. It was in fact suggested that GB migration stops once an oxide is formed along the migrating boundary [35].

Another factor that may contribute to the lower migration rate of Alloy 600TT could be a lower GB diffusivity ( $\mathrm{Dgb}$ ) locally in the surface proximity. Considering that fast diffusion in the boundary plane occurs by a vacancy mechanism with atoms moving between various sites in the boundary plane and that vacancy diffusion is affected by dislocations, the diffusivity at the boundary can increase or decrease according to the boundary local composition, the nature of the GB, and GB segregation [50,51]. In the present case, the difference in GB migration rate could also be related to the HAGB compositional differences between Alloy 600SA and Alloy 
600TT. Cr-rich $\mathrm{M}_{7} \mathrm{C}_{3}$ carbides were partially decomposed during the oxidation process and therefore they would provide a Cr reservoir for the formation of the outer oxide; however, the remaining $\mathrm{C}$ from the carbide decomposition cannot be oxidized in this reducing environment and local enrichment at the GBs has been suggested [52]. The rejected carbon can then either segregate to the GB or locally super-saturate, and change diffusion kinetics. In fact, there is experimental evidence that solid solution carbon raises the activation energy for grain boundary diffusion in Ni-16Cr-9Fe-C alloys, and lowers the grain boundary diffusivity [53]. The mechanism by which Dgb is lowered in the presence of $\mathrm{C}$ in solid solution is thought to be either due to the interaction between $\mathrm{C}$ and extrinsic grain boundary dislocations or via the direct effect between atomic $\mathrm{C}$ and vacancy mobility. It is therefore proposed that the presence of local $\mathrm{C}$ enrichment close to the GB reduces Dgb, hinders GB migration and consequently decreases intergranular oxide penetration and SCC susceptibility [10,35].

It is thought that the driving force responsible for the occurrence of DIGM is the compositional gradient between the migrated GB and the matrix [35], and that the mechanism by which migration occurs is the self-sustaining climb of grain boundary dislocations (GBDs) and motion of their associated grain boundary steps [54]. Therefore, there could be two dominant factors associated with the lower, if any at all, GB migration in Alloy 600TT during the first stages of intergranular oxidation. One factor is that local dislocation motion/climb in the Crdepleted (due to intergranular carbide precipitation) GB regions may be reduced in comparison to Alloy 600SA HAGBs due to the local C enrichment (due to carbide decomposition) at Alloy 600TT HAGBs. The second factor is the presence of coarse intergranular carbides (formed during thermal treatment) would effectively "pin" the grain boundaries making it difficult for a grain boundary to migrate at low temperature. 
The lower migration rate observed in Alloy 600TT might be another reason, together with the presence of a more protective Cr-rich surface oxide, for the lower intergranular oxidation susceptibility than Alloy 600SA. It is thought that the high GB migration rate in Alloy 600SA induces/contributes to the fracture of the brittle Cr-rich oxide surface layer exposing the $\mathrm{Cr}$ and Fe-depleted (Ni-enriched) migrated GB to the environment promoting intergranular oxidation $[10,35]$. On the other hand, because of the lower Alloy 600TT GB migration rate, the Cr-rich surface oxide might remain intact and protect the GB beneath for a prolonged time.

The migration of Alloy 600TT could not be detected in the present study. However, it is possible that this mechanism might still be active but simply have a lower kinetics. The aim of this study was to investigate the "precursor events" responsible for the initiation stages of SCC, such as the occurrence of PIO. The microstructural results clearly highlighted the increased resistance to PIO and local GB migration for Alloy 600TT; these results provide further mechanistic information and are in-line with the higher resistance of thermally-treated Alloy 600 to IGSCC initiation in PWR primary water environment [29-34], contrary to what is normally observed on sensitised austenitic stainless steels at elevated potential $[55,56]$.

\section{Conclusions}

Oxidation studies were performed on Alloy 600TT in low-pressure $\mathrm{H}_{2}$-steam at $480^{\circ} \mathrm{C}$, an environment that is known to simulate PWR primary water environment. The resulting surface and microstructure was examined using advanced AEM and were compared with previous studies on solution-annealed material tested under identical conditions:

1. Surface oxidation of thermally-treated Alloy 600 samples was characterized by homogeneously distributed intragranular Ni nodules and a bulged/bowed surface oxide structure. These findings were similar to Alloy 600SA. 
2. The intergranular Cr-rich $\mathrm{M}_{7} \mathrm{C}_{3}$ in Alloy 600TT appeared to be susceptible to decomposition during exposure in the $\mathrm{H}_{2}$-steam environment. The occurrence of carbide decomposition and subsequent presence of free $\mathrm{Cr}$ promoted the formation of a protective $\mathrm{Cr}$-rich surface oxide.

3. Alloy 600TT specimens exhibited negligible PIO susceptibility $(10-50 \mathrm{~nm})$ if compared with Alloy 600SA reported in the literature (500-1000 nm). Negligible GB migration was also observed on Alloy 600TT after oxidation.

4. The low PIO and local GB migration susceptibility of Alloy 600TT in $\mathrm{H}_{2}$-steam environment correlate very well with the enhanced resistance to IGSCC in PWR primary water environment.

5. A mechanistic interpretation is provided to account for the role of supposed $\mathrm{C}$ enrichment at GBs that is associated with the decomposition of $\mathrm{Cr}$-rich carbides. It is proposed that $\mathrm{C}$ lowers Dgb, lower the GB migration kinetics and consequently also GB intergranular oxide penetration.

\section{Acknowledgements}

The authors thanks AREVA for the financial support. Also, the authors Burke and Scenini acknowledge the EPSRC sponsored programme (EP/JO21172/1) for the financial contribution. Funding for the aberration-corrected FEI Titan G2 80-200 200S/TEM and the associated research capability of the Nuclear Advanced Manufacturing Research Centre at the School of Materials, University of Manchester, Manchester UK was provided by HM Government (UK). 


\section{References}

1. D. Van Rooyan, "Review of the stress corrosion cracking of Inconel 600." Corrosion, 31 (1975), 327-337.

2. E Serra, "Stress Corrosion Cracking of Alloy 600", EPRI Np-2114-SR (Palo Alto, CA: Electric Power Research Institute, 1981).

3. R.W. Staehle, "Occurrence of Modes and Submodes of SCC.", Proc. Control of Corrosion on the Secondary Side of Steam Generators, Houston, TX: NACE (1996), 135.

4. P.M. Scott, M. Le Calvar, "Some Possible Mechanisms of Intergranular Stress Corrosion Cracking of Alloy 600 in PWR Primary Water", in "Proceedings of the $6^{\text {th }}$ International Symposium on Environmental Degradation of Materials in Nuclear Power Systems--Water Reactors, (TMS/AIME, 1993) p. 657-670.

5. P. M. Scott, P. Combrade, "On the Mechanism of Stress Corrosion Crack Initiation and Growth in Alloy 600 Exposed to PWR Primary Water.”, In: Proceedings of the $11^{\text {th }}$ international symposium on environmental degradation of materials in nuclear power system- water reactors, minerals, metals and material society/AIME (2003).

6. Amitesh Madeshia, "An amendment to the classical model of internal oxidation: Model-inherent transition characteristic.”, Corrosion Science 68 (2013), 111-118.

7. R.C. Newman, T.S. Gendron, P.M. Scott, "Internal oxidation and embrittlement of Alloy 600.”, In: Proceedings of the $9^{\text {th }}$ international symposium on environmental degradation of materials in nuclear power system-water reactors, mineral, metals and materials society/AIME (2000), 79-93.

8. L.E. Thomas, S.M. Bruemmer, "High-resolution characterization of intergranular attack and stress corrosion cracking of Alloy 600 in high-temperature primary water.", Corrosion 55(6) (2000), 572-587. 
9. S. Lozano-Perez, J.M. Titchmarsh, "TEM investigations of intergranular stress corrosion cracking in austenitic alloys in PWR environmental conditions", Mater. High Temp. 20 (4) (2003) 573-579.

10. G. Bertali, F. Scenini, M. G. Burke, "Advanced Characterization of Alloy 600 Intergranular Oxidation”, Fontevraud 8 (2014).

11. S. Y. Persaud, A. Korinek, J. Huang, G.A. Botton, R.C. Newman, "Internal oxidation of Alloy 600 exposed to hydrogenated steam and the beneficial effects of thermal treatment." Corrosion Science 86 (2014), 108-122.

12. S.Y. Persaud, A. Korinek, R.C. Newman, "Internal oxidation of Alloy 690 in hydrogenated steam.”, Corrosion Science 90 (2015), 606-613.

13. Alisa Stratulat, David E. J. Armstrong, Steve G. Roberts, "Micro-mechanical measurement of fracture behaviour of individual grain boundaries in Ni alloy 600 exposed to a pressurized water reactor environment.”, Corrosion Science 104 (2016), 9-16.

14. R Bandy and D. Van Rooyen, "Stress Corrosion Cracking of Inconel Alloy 600 in High Temperature Water-An Update”, Corrosion, 40(8) (1984), 425-430.

15. R. B. Rebak, Z. Xia, Z. Szklarska-Smialowska, "Effect of Temperature and Cold Work on the Crack Growth Rate of Alloy 600 in Primary Water", Corrosion, 51(9) (1985), 734-738.

16. G. Economy, R. J. Jacko, and F. W. Pement, "IGSCC Behavior of Alloy 600 Steam Generator Tubing in Water or Steam Tests Above $360^{\circ} C^{\prime \prime}$, Corrosion 43(12) (1987), 727-734.

17. Y. Yamamoto, M. Ozawa, K. Nakata, T. Tsuruta, M. Sato, T. Okabe; "Evaluation of Crack Growth Rate for Alloy 600TT SG Tubing in Primary and Faulted Secondary 
Water Environments"; in "Proceedings of the 12th International Symposium on Environmental Degradation of Materials in Nuclear Power Systems--Water Reactors," (AIME, 2005).

18. R Bandy, D. Van Rooyen, "Stress corrosion cracking of Inconel alloy 600 in high temperature water- an update.”, Corrosion, 40(8) (1984), 425-430.

19. R.B. Rebak, Z. Szklarska-Smialowska, "The mechanism of stress corrosion cracking of Alloy 600 in high temperature water.”, Corrosion Science, 38(6) (1996), 971-988.

20. H. A. Domian, R. H. Emanuelson, L. W. Sarver, G. J. Theus, L. Katz, "Effect of microstructure on stress corrosion cracking of Alloy 600 in high purity water.", Corrosion 33 (1) (1977), 26.

21. N. Pessal, G. P. Airey, and B. P. Lingenfelter, "The Influence of Thermal Treatment on the SCC Behavior of Inconel Alloy 600 at Controlled Potentials in 10\% Caustic Soda Solutions at $315^{\circ} \mathrm{C} . "$ Corrosion, 35 (1979), 100-107.

22. G. Economy, R. J. Jacko, and F. W. Pement, "IGSCC Behavior of Alloy 600 Steam Generator Tubing in Water or Steam Tests Above $360^{\circ}$ C", Corrosion, 43 (1987), 727 734.

23. T. S. Bulischeck, D. Van Rooyen, "Stress Corrosion cracking of Alloy 600 using the constant strain rate test.”, Corrosion 37 (1981), 597-607.

24. K. Norring, J. Engstrom, P. Norberg, "Intergranular stress corrosion cracking in steam generator tubing. Testing of Alloy 600 and Alloy 690 tubes.", in "Proceedings of the $3^{\text {rd }}$ International Symposium on Environmental Degradation of Materials in Nuclear Power Systems--Water Reactors, (TMS/AIME, 1987), 587-593.

25. G.S. Was, K. Lian, "Isolation of carbon and grain boundary carbides effects on the creep and intergranular stress corrosion cracking behaviour of $\mathrm{Ni}-16 \mathrm{Cr}-9 \mathrm{Fe}-\mathrm{xC}$ alloys in $360^{\circ} \mathrm{C}$ primary water." Metall. Mater. Trans. A 29 (1998), 1035-1046. 
26. B. Alexandreanu, B. Capell, G.S. Was, "Combined effect of special grain boundaries and grain boundaries carbideson IGSCC of Ni-16Cr-9Fe-xC alloys." Material Sci. Eng. A300 (2001), 94-104.

27. G.P. Airey, "Optimization of Metallurgical Variables to Improve the Stress Corrosion Resistance of Inconel 600.” EPRI NP-3051 (Paolo Alto, CA: Electric Power Research Institute 1983).

28. R.B. Rebak, Z. Xia, S. Szklarska-Smialowska, "Effect of carbides on susceptibility of Alloy 600 to stress corrosion cracking in high-temperature water." Corrosion 49 (1993), 867-876.

29. S. M. Bruemmer, L. A. Charlot, C. H. Henager, "Microstructure and microdeformation effects on IGSCC of Alloy 600 steam generator tubing." Corrosion, 44 (1988), 782788.

30. G. S. Was, K. Lian, "Role of carbides in stress corrosion cracking resistance of Alloy 600 and controlled-purity $\mathrm{Ni}-16 \% \mathrm{Cr}-9 \% \mathrm{Fe}$ in primary water at $360^{\circ} \mathrm{C}$." Corrosion, 54 (1998), 675-688.

31. M. G. Burke, W. C. Moshier, G. J. C. Carpenter and M. W. Phaneuf, "Characterization of Intergranular Fracture in a Ni-Cr-Fe Alloy using SEM, FIB and AEM Techniques" Microscopy and Microanalysis, 10 (2004) 1140-41.

32. H. Dugdale, David E. J. Armstrong, Edmund Tarleton, Steve G. Roberts, Sergio Lozano Perez, "How oxidized grain boundaries fail.” Acta Materialia, 61 (2013), 4707-4713.

33. M. Sennour, P. Laghoutaris, C. Guerre, R. Molins, “ Advanced TEM characterization of stress corrosion cracking of Alloy 600 in pressurized water reactor primary water environment.”, Journal of Nuclear Materials 393 (2009), 254-266.

34. R. Morris, N. Lewis, D. S. Morton, “3D Analysis of Surface Treatment Effects on the Oxidation of Grain Boundaries in Alloy 600." in "Proceedings of the $16^{\text {th }}$ International 
Symposium on Environmental Degradation of Materials in Nuclear Power Systems-Water Reactors," (NACE, 2013).

35. G. Bertali, F. Scenini, M.G. Burke, “Advanced Microstructural Characterization of Alloy 600 Intergranular Oxidation.”, Corrosion Science 100 (2015), 474-483.

36. M. J. Olszta, D. K. Schreiber, L. E. Thomas, S. M. Bruemmer, “Electron Microscopy Characterizations and Atom Probe Tomography of Intergranular Attack in Alloy 600 Exposed to PWR Primary Water.", in "Proceedings of the $15^{\text {th }}$ International Symposium on Environmental Degradation of Materials in Nuclear Power Systems-Water Reactors, (TMS/NACE, 2011).

37. M.J. Olszta, D.K. Schreiber, M.B. Toloczko, S.M Bruemmer, “ Alloy 690 Surface Nanostructures During Exposure to PWR Primary Water and Potential Influence on Stress Corrosion Cracking Initiation.”, In: Proceedings of the 16th international symposium on environmental degradation of materials in nuclear power system-water reactors, (TMS/NACE, 2013).

38. D.K. Schreiber, M.J. Olszta, D.W. Saxey, K. Kruska, K.L. Moore, S. Lozano-Perez, S.M. Bruemmer, "Examinations of Oxidation and Sulfidation of Grain Boundaries in Alloy 600 Exposed to Simulated Pressurized Water Reactor Primary Water.”, Microscopy \& Microanalysis 19 (2013), 676-687.

39. S. Y. Persaud, J. Smith, A. Korinek, G. A. Botton, R. C. Newman, "High Resolution Analysis of Oxidation in Ni-Fe-Cr Alloys after Exposure to $315^{\circ} \mathrm{C}$ Deaerated Water added Hydrogen.” Corrosion Science 106 (2016), 236-248.

40. M. G. Burke, G. Bertali, E. Prestat, F. Scenini, S. J. Haigh, “The Application of In Situ Analytical Transmission Electron Microscopy to the Study of Preferential Intergranular Oxidation in Alloy 600.”, Ultramicroscopy 2016, accepted . 
41. B. Chen, J.N. Hu, P.E.J. Flewitt, A.C.F. Cocks, R.A. Ainsworth, D.J. Smith, D.W. Dean, and F. Scenini, "Effect of thermal ageing on creep and oxidation behavior of Type 316H stainless steel.”, Materials at High Temperatures 32 (2015), 592-606.

42. F. Scenini, R.C. Newman, R.A. Cottis and R.J. Jacko, "Effect of Surface Preparation on Intergranular Stress Corrosion Cracking of Alloy 600 in Hydrogenated Steam.”, Corrosion 64 (2008), 824-835.

43. D. Morton, S.A. Attanasio, G. Young, "Primary water SCC understanding and characterization through fundamental testing in the vicinity of the Nickel/Nickel oxide phase transition.", In: Proceedings of the $10^{\text {th }}$ international symposium on environmental degradation of materials in nuclear power system-water reactors, mineral, metals and materials society/NACE (2001).

44. Staehle, R.W. and J.A. Gorman, "Quantitative Assessment of Submodes of Stress Corrosion Cracking on the Secondary Side of Steam Generator Tubing in Pressurized Water Reactors: Part 1.” Corrosion 59(11) (2003), 931-994

45. F. Scenini, R.C Newman, R.A Cottis, R.J. Jacko, “Alloy 600 Oxidation Studies Related to PWSCC.", in "Proceedings of the $12^{\text {th }}$ International Symposium on Environmental Degradation of Materials in Nuclear Power Systems--Water Reactors," (TMS/AIME (2005).

46. B. Langelier, S. Y. Persaud, R. C. Newman, G. A. Botton, “An atom probe tomography study of internal oxidation processes in Alloy 600.", Acta Materialia 109 (2016), 5568.

47. G. Bertali, F. Scenini, M. G. Burke, "The effect of residual stress on the Preferential Intergranular Oxidation of Alloy 600”, Corrosion Science 111 (2016), 494-507. 
48. P. Laghoutaris, “Corrosion sus contrainte de l'alliage 600 en milieu primaire des réacteurs à eau sous pression: apport à a la comprehension des mécanismes”, $\mathrm{PhD}$ thesis, Ecole Nationale Superieure des Mines de Paris, France, 2009.

49. Yun Soo Lim, Sung Woo Kim, Seong Sik Hwang, Hong Pyo Kim, Changheui Jang, "Intergranular oxidation of Ni-based Alloy 600 in a simulated PWR primary water environment.", Corrosion Science 108 (2016), 125-133.

50. E. L. Hall and C.L. Briant, "Intergranular Corrosion of High-Chromium Nickel-base Alloys.” Corrosion 43 (7) (1987) 437-440.

51. E.D Hondros, M.P. Seah, “Segregation to interfaces.”, Intl. Metal Rev. ,222 (1977), 262-301.

52. G. Bertali, F. Scenini, M. G. Burke, "Solution-annealed and thermally-treated Alloy 600 preferential intergranular oxidation: a comparison.", in "Proceedings of the $17^{\text {th }}$ International Symposium on Environmental Degradation of Materials in Nuclear Power Systems-Water Reactors,” (TMS/AIME (2015).

53. J.L Hertzberg, G.S Was, "The effect of carbon on grain boundary diffusivity in Ni16Cr-9Fe alloys.”, Scripta Metallurgica et Materialia, 33(8) (1995),1193-1199.

54. R.W. Balluffi, J.W. Cahn, "Mechanism for diffusion induced grain boundary migration), Acta Metallurgica, ,29(3) (1981), 493-500.

55. F. Scenini, and A.H. Sherry, "SCC of Sensitized 304SS in High Temperature Water With Anionic Impurities Contamination”, Corrosion, 68(12) (2012), 1094-1107.

56. Scenini, F., Govender, K., Lyon, S., \& Sherry, A. (2012). Stress corrosion cracking of Ru doped 304 stainless steel in high temperature water. Corrosion Engineering Science and Technology, 47(7), 498-506. 
Images caption

Figure 1: SEM BSE image of polished Alloy 600TT.

Figure 2: BSE images of the intergranular darkly-imaging carbides and of the intragranular precipitates.

Figure 3: BSE image of Alloy 600TT cross-section which contains a HAGB showing no surface etching or pre-existing carbides decomposition.

Figure 4: (a) TEM BF and (b) DF images of Alloy 600TT showing the presence of intragranular carbides, which were identified via electron diffraction as $\mathrm{M}_{23} \mathrm{C}_{6}$ (insert in Figure b).

Figure 5: : (a) TEM BF and (b) DF images of Alloy 600TT showing the presence of intergranular carbides, which were identified via electron diffraction as $\mathrm{M}_{7} \mathrm{C}_{3}$ (insert in Figure b).

Figure 6: (a) TEM BF and (b) DF images of Alloy 600TT showing the presence of intergranular carbides, which were identified via electron diffraction as $\mathrm{M}_{23} \mathrm{C}_{6}$ (insert in Figure $\mathrm{b}$ ).

Figure 7: STEM-HAADF image and corresponding SSD-EDX spectrum images of electropolished Alloy 600TT showing the Intergranular $\mathrm{Cr}$-rich $\mathrm{M}_{23} \mathrm{C}_{6}$ and $\mathrm{M}_{7} \mathrm{C}_{3}$ carbides and the extent of GB Cr-depletion before the exposure in $\mathrm{H}_{2}$-steam environment.

Figure 8: SE image of the oxidized surface morphology of Alloy 600TT specimen after 120 hours in $\mathrm{H}_{2}$-steam at $480{ }^{\circ} \mathrm{C}$. 
Figure 9: (a) SE and (b) BSE images of an HAGB after 120 hours of exposure in $\mathrm{H}_{2}$-steam environment at $480{ }^{\circ} \mathrm{C}$ showing the protruded GB regions and the darkly-imaging line at the HAGB.

Figure 10: (a) SE and (b) BSE images of an HAGB after 120 hours of exposure in $\mathrm{H}_{2}$-steam environment at $480{ }^{\circ} \mathrm{C}$ showing the protruding GB regions and the straight darkly-imaging line at the HAGB.

Figure 11: BSE image of Alloy 600TT cross-section obtained from an oxidized HAGB after 120 hours exposure at $480^{\circ} \mathrm{C}$ in $\mathrm{H}_{2}$-steam environment, the surface was characterized by a bulged oxide morphology, showing the presence of superficial darkly-imaging oxide and of decomposed carbide.

Figure 12: TEM BF (a) and DF with relative selected area diffraction pattern (SADP) (b) images showing the possible occurrence of decomptosition of the interganular $\mathrm{M}_{7} \mathrm{C}_{3}$, after 120 hours exposure at $480^{\circ} \mathrm{C}$ in $\mathrm{H}_{2}$-steam environment.

Figure 13: STEM-HAADF image and corresponding SSD-EDX spectrum images of the decomposed intergranular carbides after 120 hours exposure at $480{ }^{\circ} \mathrm{C}$ in $\mathrm{H}_{2}$-steam environment showing the presence of a surface Cr-rich oxide above the GB. The intergranular carbide decomposition is confirmed from the $\mathrm{Cr} \mathrm{K} \alpha$ spectrum image.

Figure 14: STEM-HAADF image and corresponding SSD-EDX spectrum images of an oxidized HAGB after 120 hours exposure at $480^{\circ} \mathrm{C}$ in $\mathrm{H}_{2}$-steam environment, showing the presence of an external Cr-rich oxide, an embryo of Cr-rich intergranular oxide and the occurrence of Cr-rich $\mathrm{M}_{7} \mathrm{C}_{3}$ decomposition. 


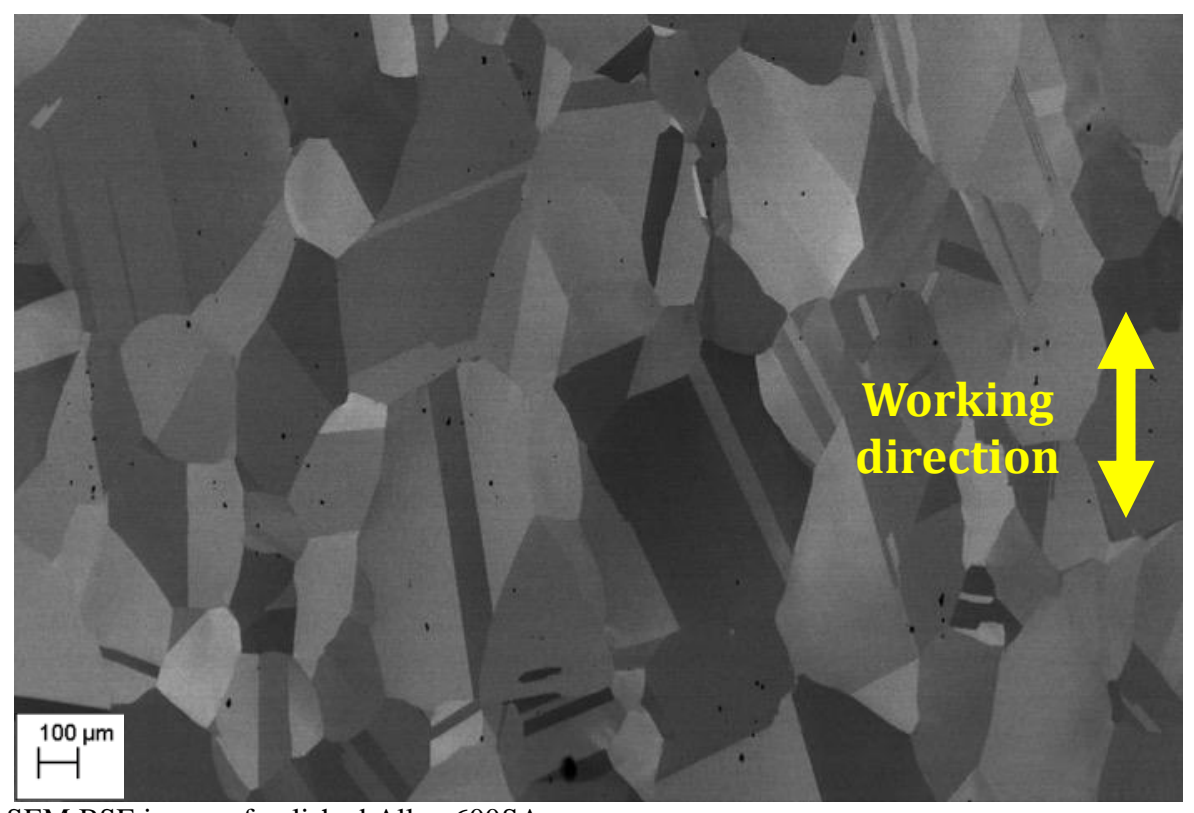

Figure 1: SEM BSE image of polished Alloy 600SA.

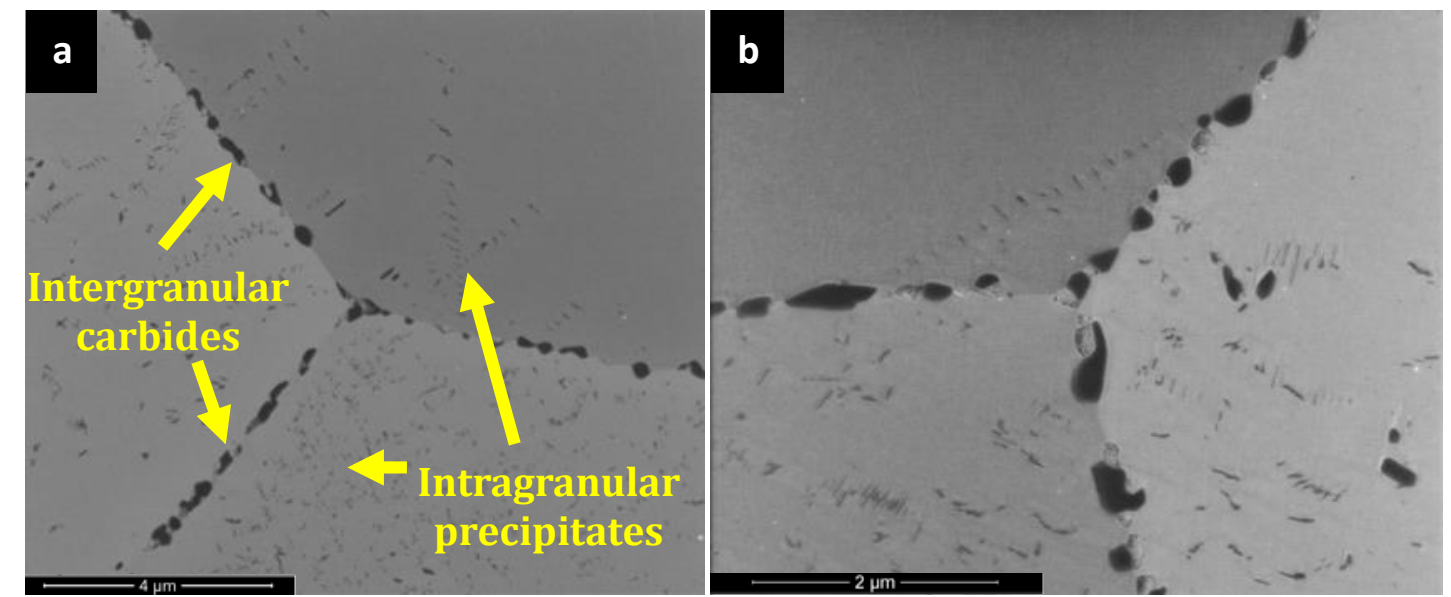

Figure 2: BSE images of the intergranular darkly-imaging carbides and of the intragranular precipitates.

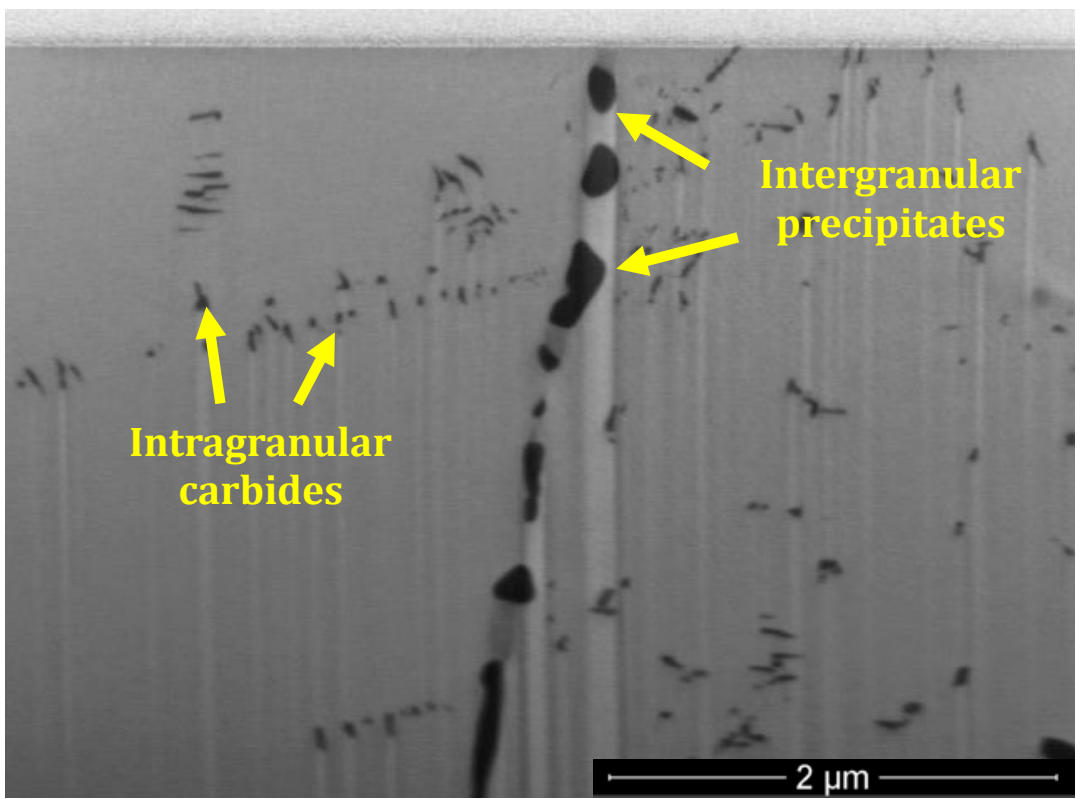

Figure 3: BSE image of Alloy 600TT cross-section which contains a HAGB showing no surface etching or preexisting carbides consumption. 


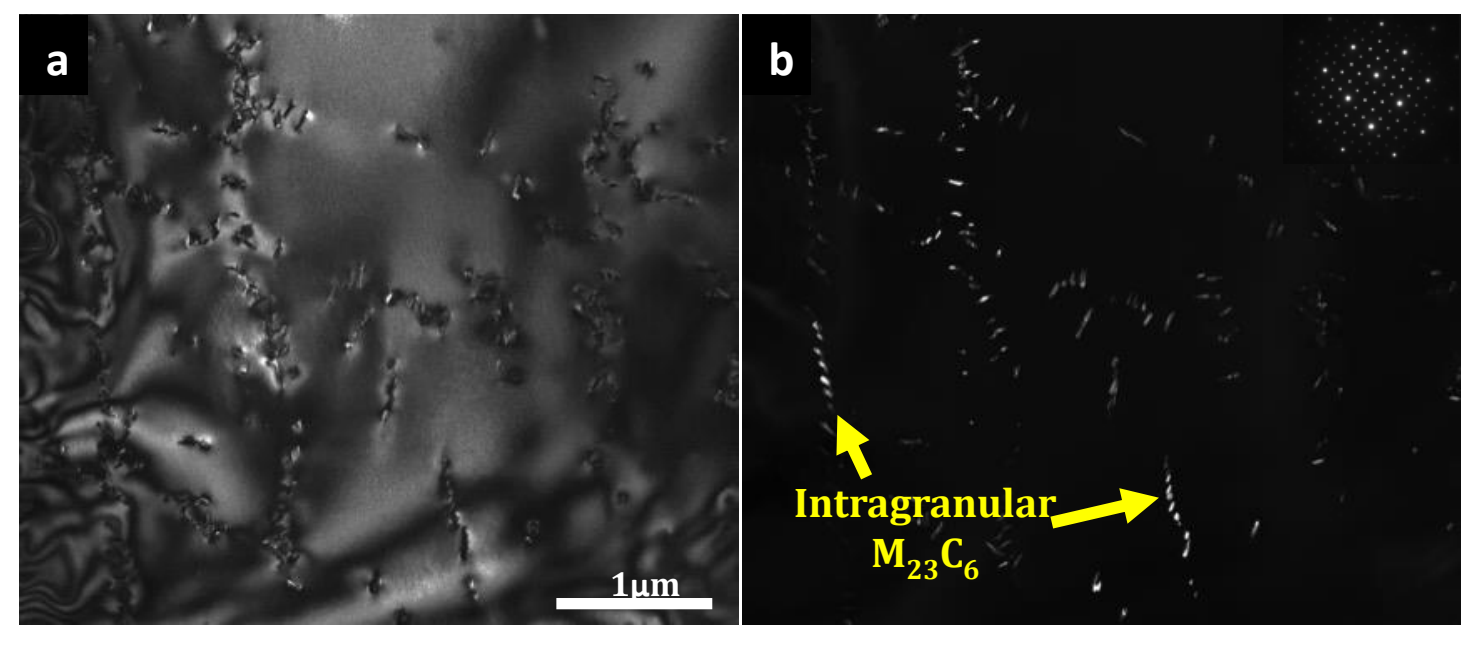

Figure 4: TEM DF images of Alloy 600TT showing the presence of transgranular Cr-carbides, which were identified via electron diffraction as $\mathrm{M}_{23} \mathrm{C}_{6}$ (insert in Figure b).

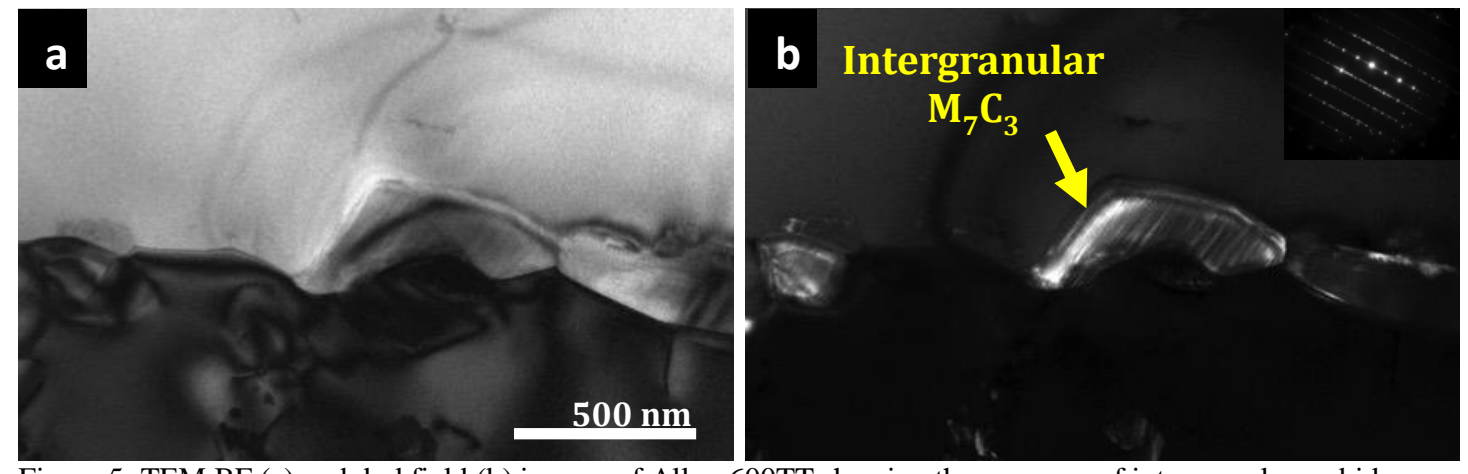

Figure 5: TEM BF (a) and darkfield (b) images of Alloy 600TT showing the presence of intergranular carbides, which were identified via electron diffraction as $\mathrm{M}_{23} \mathrm{C}_{6}$ (insert in Figure $b$ ).

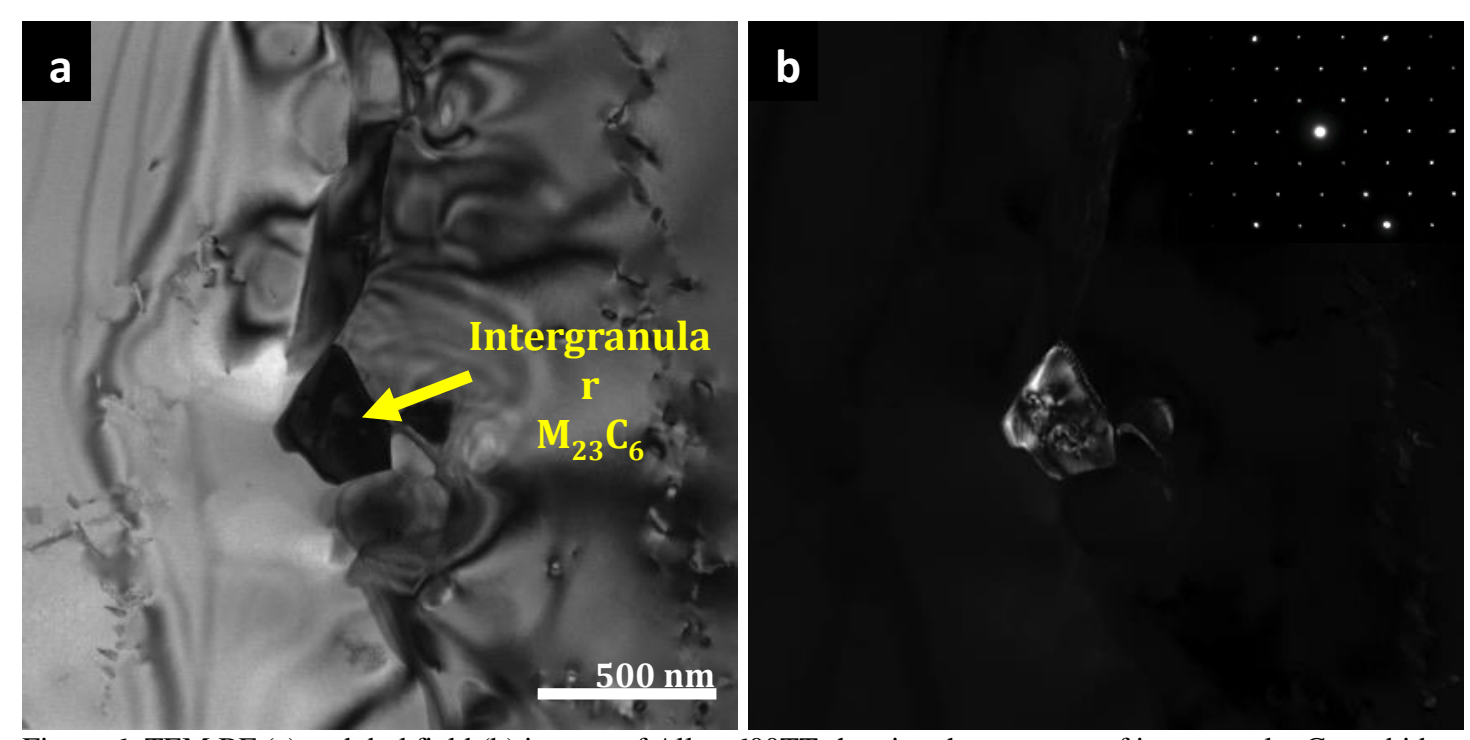

Figure 6: TEM BF (a) and darkfield (b) images of Alloy 600TT showing the presence of intergranular Cr-carbides, which were identified via electron diffraction as $\mathrm{M}_{23} \mathrm{C}_{6}$. 


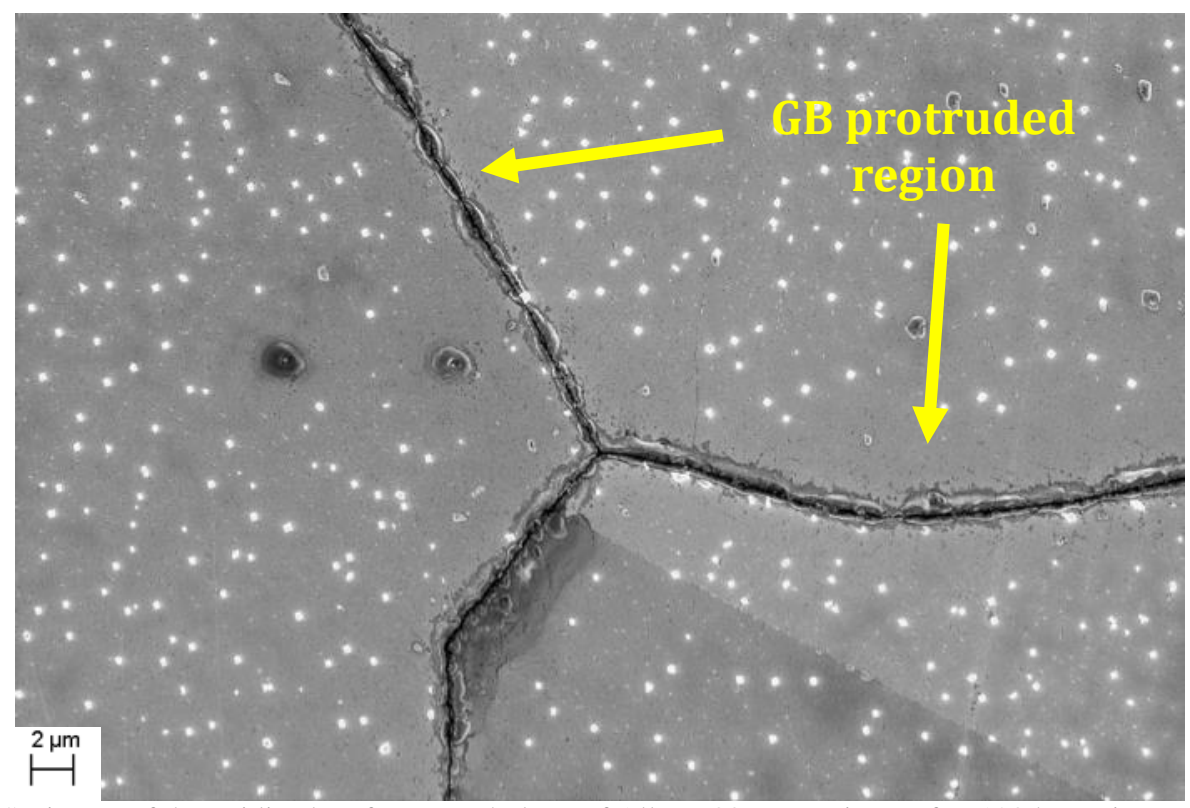

Figure 7: SE image of the oxidized surface morphology of Alloy 600TT specimen after 120 hours in $\mathrm{H}_{2}$-steam at $480{ }^{\circ} \mathrm{C}$.

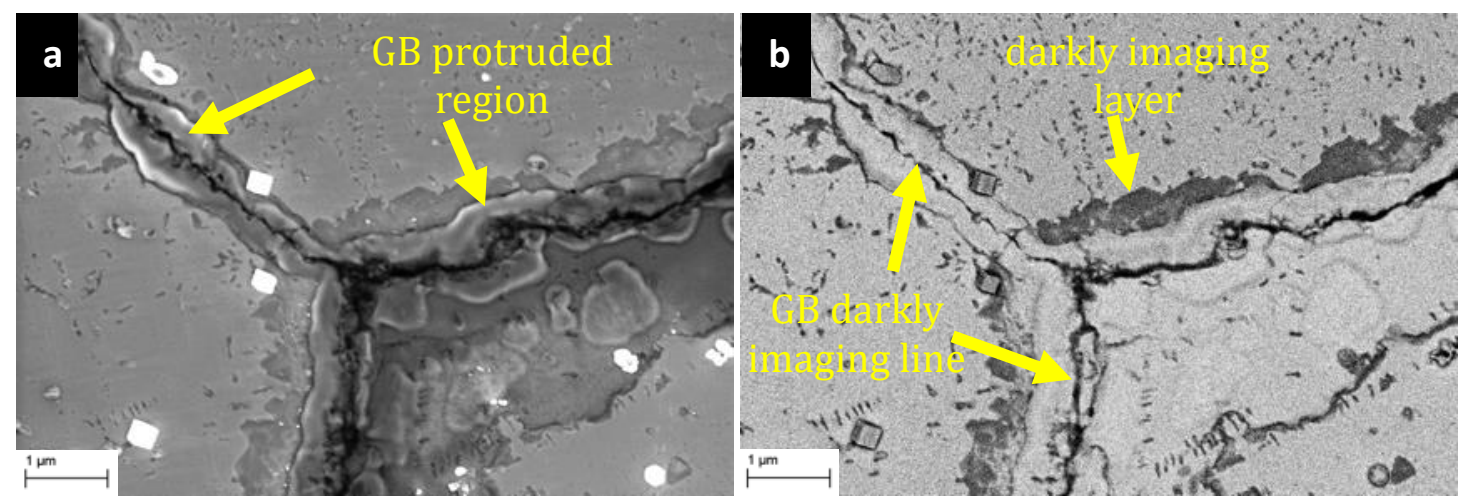

Figure 8: (a) SE and (b) BSE images of an HAGB after 120 hours of exposure in $\mathrm{H}_{2}$-steam environment at $480{ }^{\circ} \mathrm{C}$ showing the protruded GB regions and the darkly-imaging line at the HAGB.
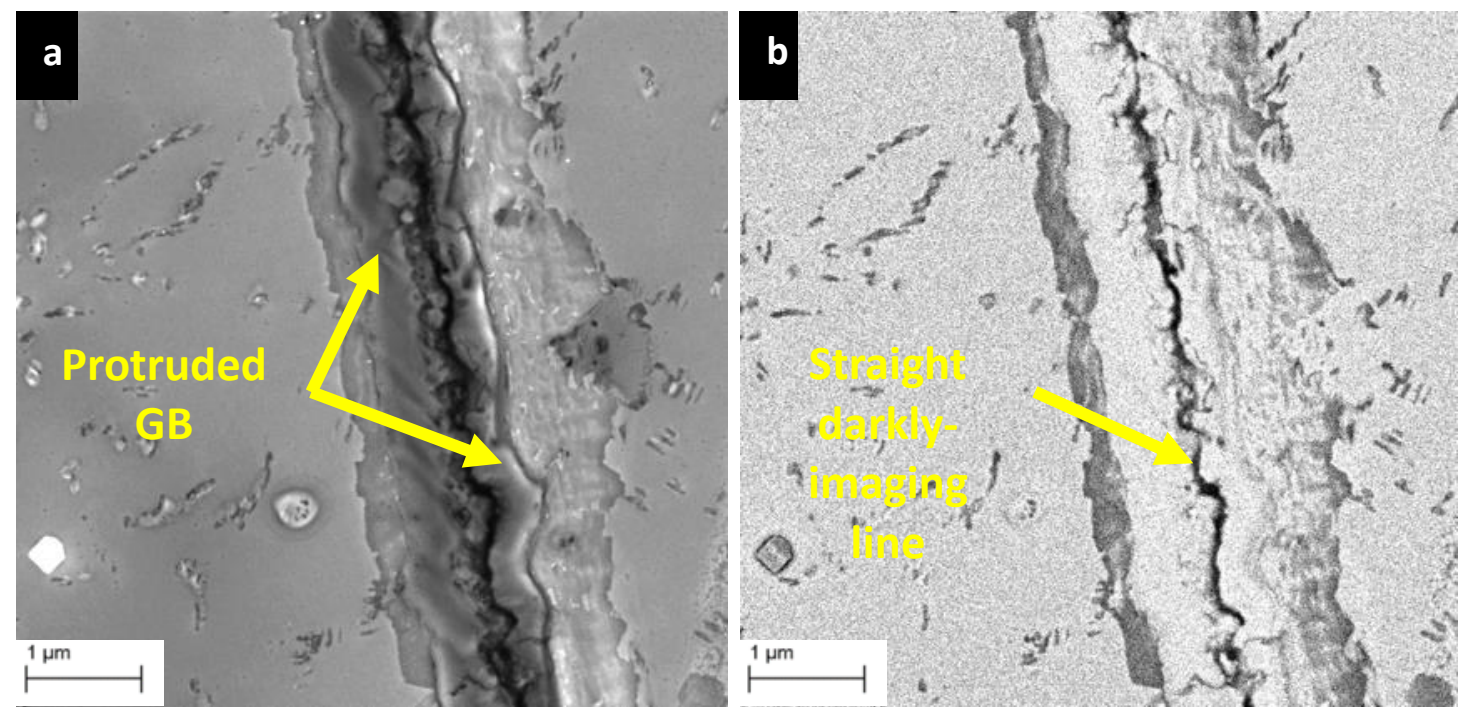

Figure 9: (a) SE and (b) BSE images of an HAGB after 120 hours of exposure in $\mathrm{H}_{2}$-steam environment at $480{ }^{\circ} \mathrm{C}$ showing the protruding GB regions and the straight darkly-imaging line at the HAGB. 


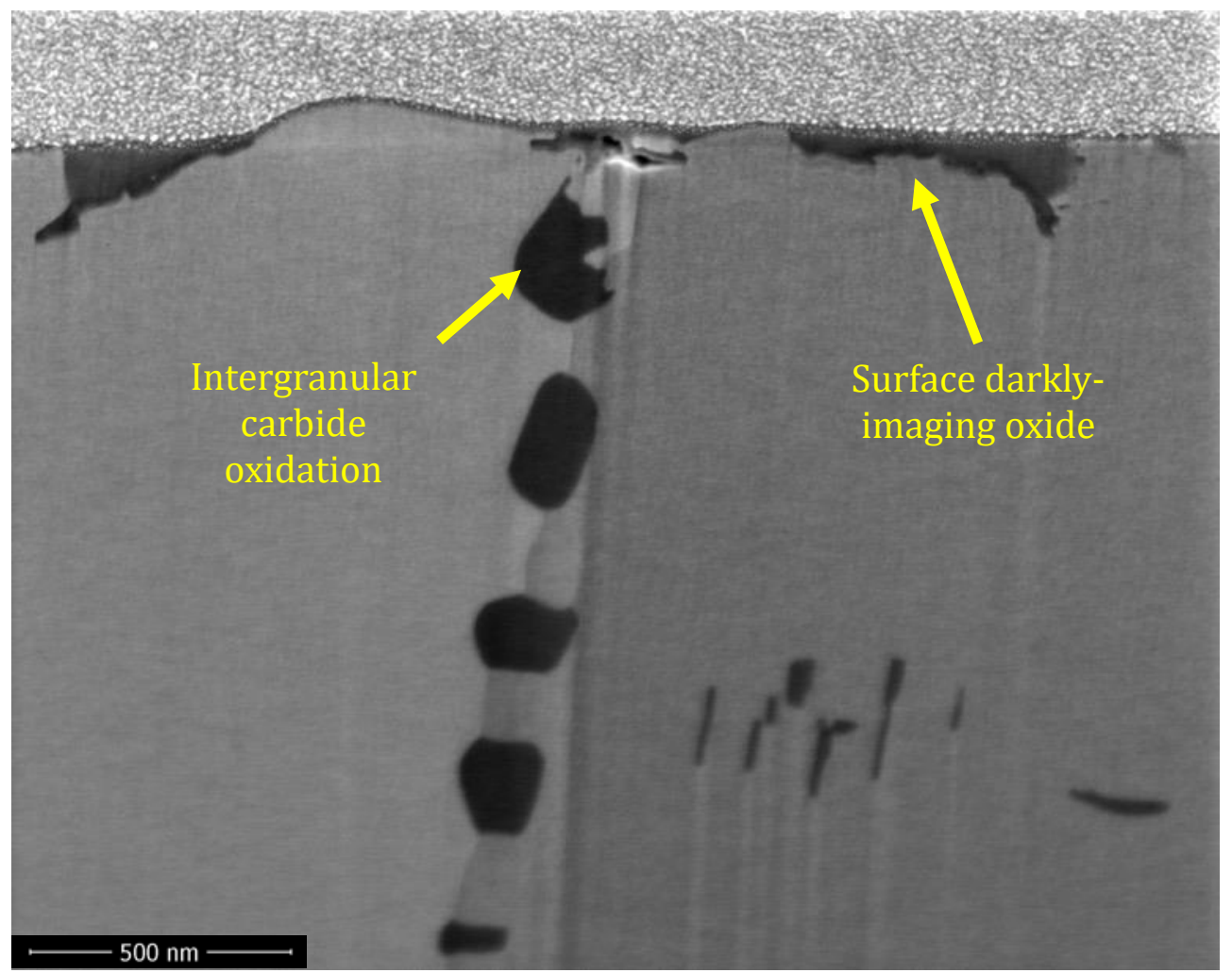

Figure 10: BSE image of Alloy 600TT cross-section obtained from an oxidized HAGB after 120 hours exposure at $480^{\circ} \mathrm{C}$ in $\mathrm{H}_{2}$-steam environment, the surface was characterized by a bulged oxide morphology, showing the presence of superficial darkly-imaging oxide and of oxidized/consumed carbide.
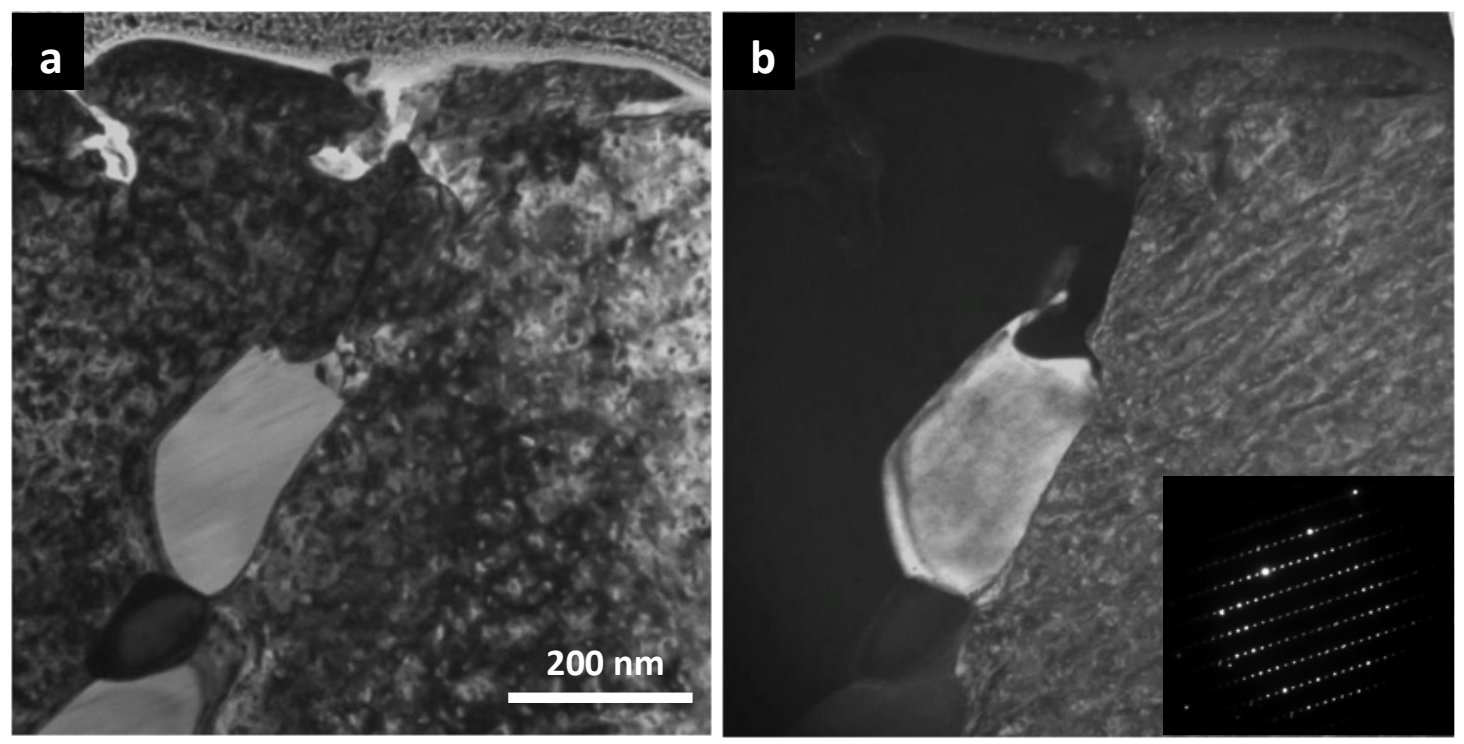

Figure 11: TEM BF (a) and DF with relative selected area diffraction pattern (SADP) (b) images showing the possible occurrence of oxidation of the interganular $\mathrm{M}_{7} \mathrm{C}_{3}$, after 120 hours exposure at $480^{\circ} \mathrm{C}$ in $\mathrm{H}_{2}$-steam environment. 


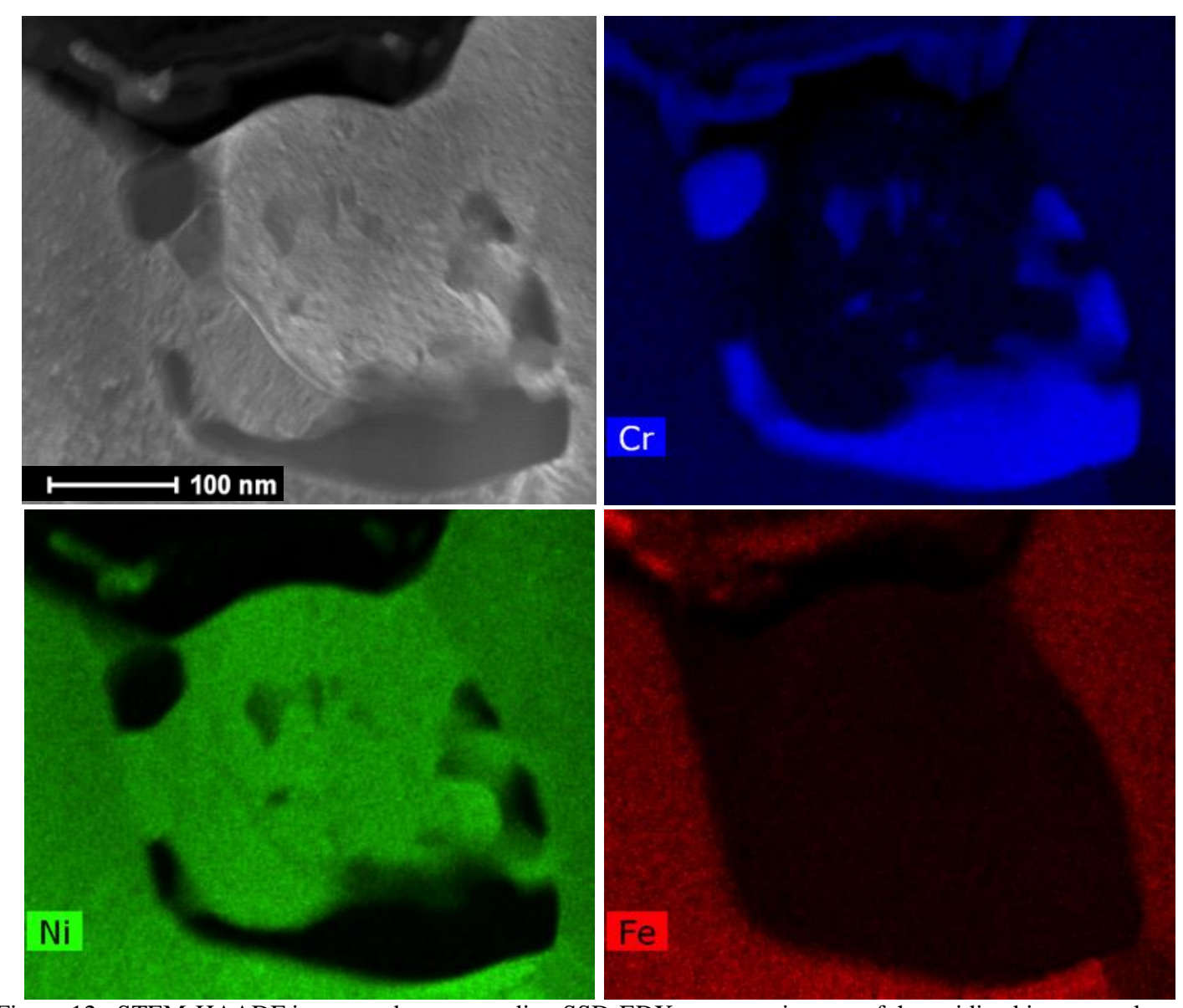

Figure 12: STEM-HAADF image and corresponding SSD-EDX spectrum images of the oxidized intergranular carbides after 120 hours exposure at $480{ }^{\circ} \mathrm{C}$ in $\mathrm{H}_{2}$-steam environment., showing the presence of a surface $\mathrm{Cr}$-rich oxide above the GB. The intergranular carbide consumption is confirmed from the $\mathrm{Cr} \mathrm{K} \alpha$ spectrum image.

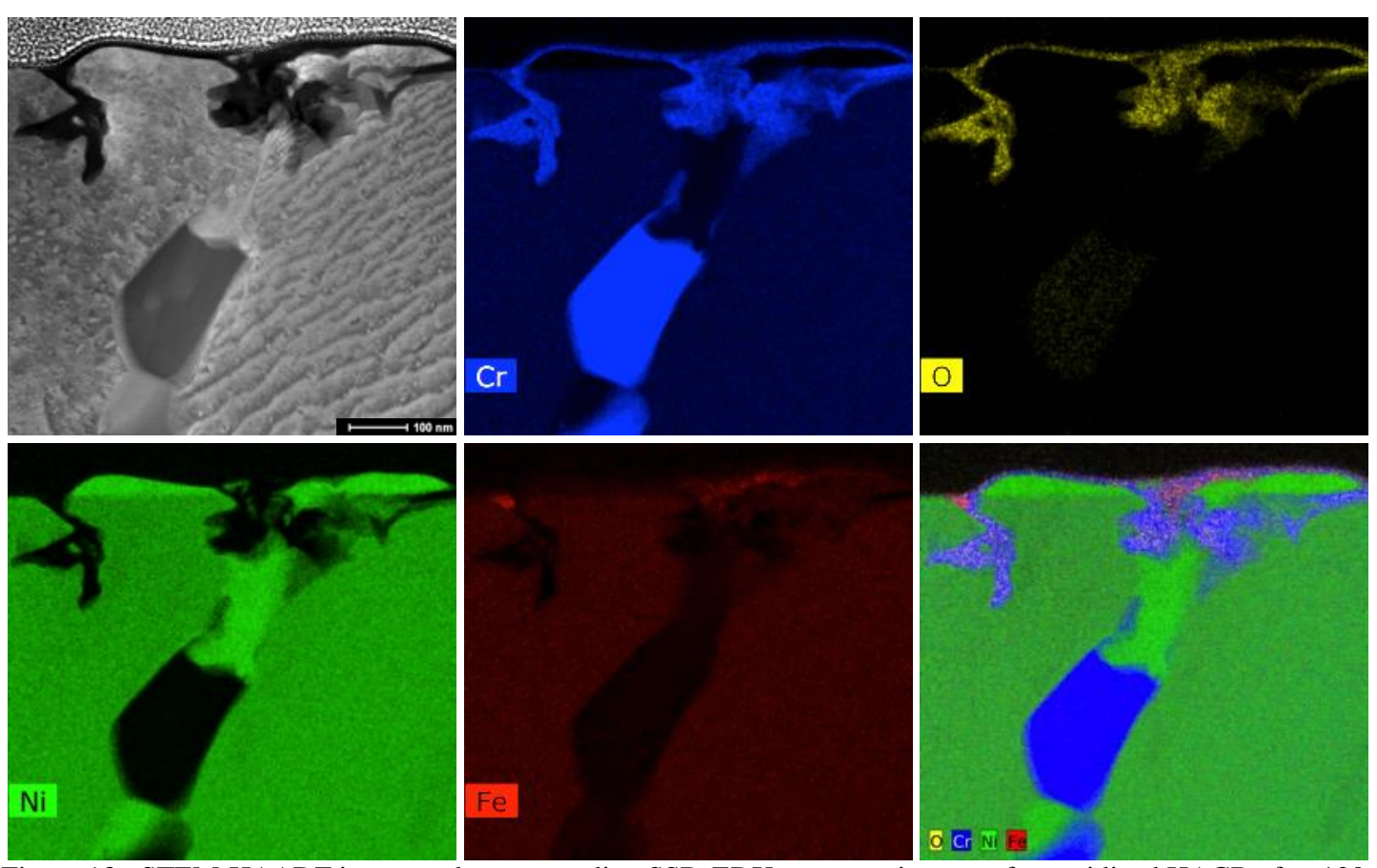

Figure 13: STEM-HAADF image and corresponding SSD-EDX spectrum images of an oxidized HAGB after 120 hours exposure at $480^{\circ} \mathrm{C}$ in $\mathrm{H}_{2}$-steam environment, showing the presence of an external $\mathrm{Cr}$-rich oxide, an embryo of $\mathrm{Cr}$-rich intergranular oxide and the occurrence of $\mathrm{Cr}$-rich $\mathrm{M}_{7} \mathrm{C}_{3}$ oxidation. 